\title{
Comparison of the LTE Performance Parameters in Different Environments under Close Loop Spatial Multiplexing (CLSM) Mode in Downlink LTE-A
}

\author{
Syed Rafiee Abied, Abdullah Bin Shams, Mohammad T. Kawser \\ Department of Electrical and Electronic Engineering, Islamic University of Technology, Gazipur, Bangladesh \\ Email: rafiee.abied@gmail.com, abdullahbinshams@gmail.com, mkawser@hotmail.com
}

How to cite this paper: Abied, S.R., Shams, A.B. and Kawser, M.T. (2017) Comparison of the LTE Performance Parameters in Different Environments under Close Loop Spatial Multiplexing (CLSM) Mode in Downlink LTE-A. Journal of Computer and Communications, 5, 117-128. https://doi.org/10.4236/jcc.2017.59008

Received: June 24, 2017

Accepted: July 18, 2017

Published: July 21, 2017

Copyright $\odot 2017$ by authors and Scientific Research Publishing Inc. This work is licensed under the Creative Commons Attribution International License (CC BY 4.0).

http://creativecommons.org/licenses/by/4.0/

\begin{abstract}
LTE-A present deployment strategies are likely to overcome the User Equipment (UE) performance degradation, in certain parts of the topology incorporated with coverage block holes, due to the presence of high rise buildings. It also promises to serve the increase of high user density, which otherwise results in capacity exhaustion of the macro cells. LTE-A addresses these challenges with new features such as small cell and femto cell in its recent releases. Small cell is a low-cost alternative to macro cell in rural and hard-to-reach areas and its installation at strategic points overcomes the capacity and coverage problem. In contrast, Heterogeneous network with its ubiquitous coverage can deliver high-speed data. In this paper, several LTE Key performance indicators e.g. average UE throughput, average area throughput, spectral efficiency, fairness index are analyzed between small cell network and Heterogeneous network in close loop spatial multiplexing mode (CLSM). Besides, we also emphasize on the point to find out the best suited network architecture for overpopulated and densely urban region under proportional fair scheduling algorithm.
\end{abstract}

\section{Keywords}

LTE, CLSM, Small Cell, Heterogeneous Network, UE Throughput, Spectral Efficiency

\section{Introduction}

LTE is a 3rd Generation Partnership Project (3GPP) standard designed to take cellular technology to the next dimension by providing improved system cover- 
age, capacity, efficient spectrum utilization, lower latency and high data speed. Moreover, LTE allocated bandwidths, ranging from $1.4 \mathrm{MHz}$ up to $20 \mathrm{MHz}$, are supported in TDD unpaired and FDD paired spectrums. For downlink transmission Orthogonal Frequency Division Multiple Access (OFDMA), scheme is implemented to improve throughput and spectral efficiency while for uplink transmission Single Carrier Frequency Division Multiple Access (SC-FDMA), scheme is used for getting low Peak to Average power ratio (PAPR) [1]. LTE offers several MIMO modes to acquire high-data rate and better spectral efficiency for the UEs both in the uplink and downlink. A maximum data rate of 326.4 Mbps and 86.4 Mbps can be achieved in the downlink and uplink respectively for a $20 \mathrm{MHz}$ channel [2]. Conventional macro cell network experiences several problems for ubiquitous coverage especially in urban environments. Moreover with increase in user density, capacity exhaustion of macro cells is inevitable. To overcome these and other similar obstacles for better UE performance, LTE introduced multiple features [3]. The potential aspects in the latest 3GPP releases are small cell and femto cell to meet high traffic demand and better network coverage.

Several researches have done regarding on the performance of small cell [4] [5] [6]. Researchers have also done analysis on energy efficiency of CoMP based green communication [7] [8] [9]. But the authors did not consider the effect of small cell, heterogeneous network, scheduler performances and MIMO schemes. Heterogeneous network performances under different resource scheduling algorithm have already analyzed [10] [11]. Performances of heterogeneous network in different spatial multiplexing mode have done under mobile cases [12]. These aforementioned research articles are mainly focused on the user performances. But in our work we have examined LTE performance parameters for both user and network perspective. Besides, in this paper, we have compared the downlink parameters between small cell network and heterogeneous network (which actually incorporate with macro cell and femto cell) to assess which type of cell deployment provides greater network and device efficiency.

The remainder of the paper is organized as follows: Section II contains LTE features for improved and UE efficiency, Section III contains brief summary on network model and simulation are discussed in section IV. Results and discussions are described in section $\mathrm{V}$ and finally the conclusions are drawn in section VI.

\section{LTE Features for Improved Network and UE Efficiency}

\subsection{Small Cell Network}

Small cell has become a vital solution to improve system capacity within the coverage area of a network and deployed in areas of heavy traffic depending on the position of the user distribution. Small cells ensure better network performance and Quality of Service (QoS) by offloading data from the large macrocells. 


\subsection{Heterogeneous Network}

The Femto cell in LTE has a coverage radius of $50-200 \mathrm{~m}$, can bear $2-8$ users concurrently and radiating very low power $(<10 \mathrm{~mW})$. Better indoor voice and data reception, low deployment cost and improved battery life are provided in femto cell that benefits both the users and operators. Average Revenue per User (ARPU) is increased and the capital spent per user on new macro cell equipment is reduced simultaneously from the operator perspective in femto cell. On the other hand, macro cell is a high power base station covering a larger area. To form a heterogeneous network, femto cell is used in network depleted areas with macro cell to provide a ubiquitous network.

\section{Network Model}

To analyze the performance of small cell and heterogeneous network mentioned in section II, individual strategies were employed. From Figure 1, it can be seen that small cell network comprising of 19 BSs are deployed in hexagonal order where each BS is separated from each other by $150 \mathrm{~m}$.

Figure 2 illustrates, heterogeneous network deployment where single antenna represents femto cell and tri sector antenna represents macro cell. For heterogeneous network in Figure 2, we have used 20 femto cells that are placed by Poisson point process (PPP) and 19 BSs which are placed in hexagonal order as macro cell. Here the macro cells are separated from each other by $500 \mathrm{~m}$.

In both cases, for our simulation we have considered 570 UEs which are ran-

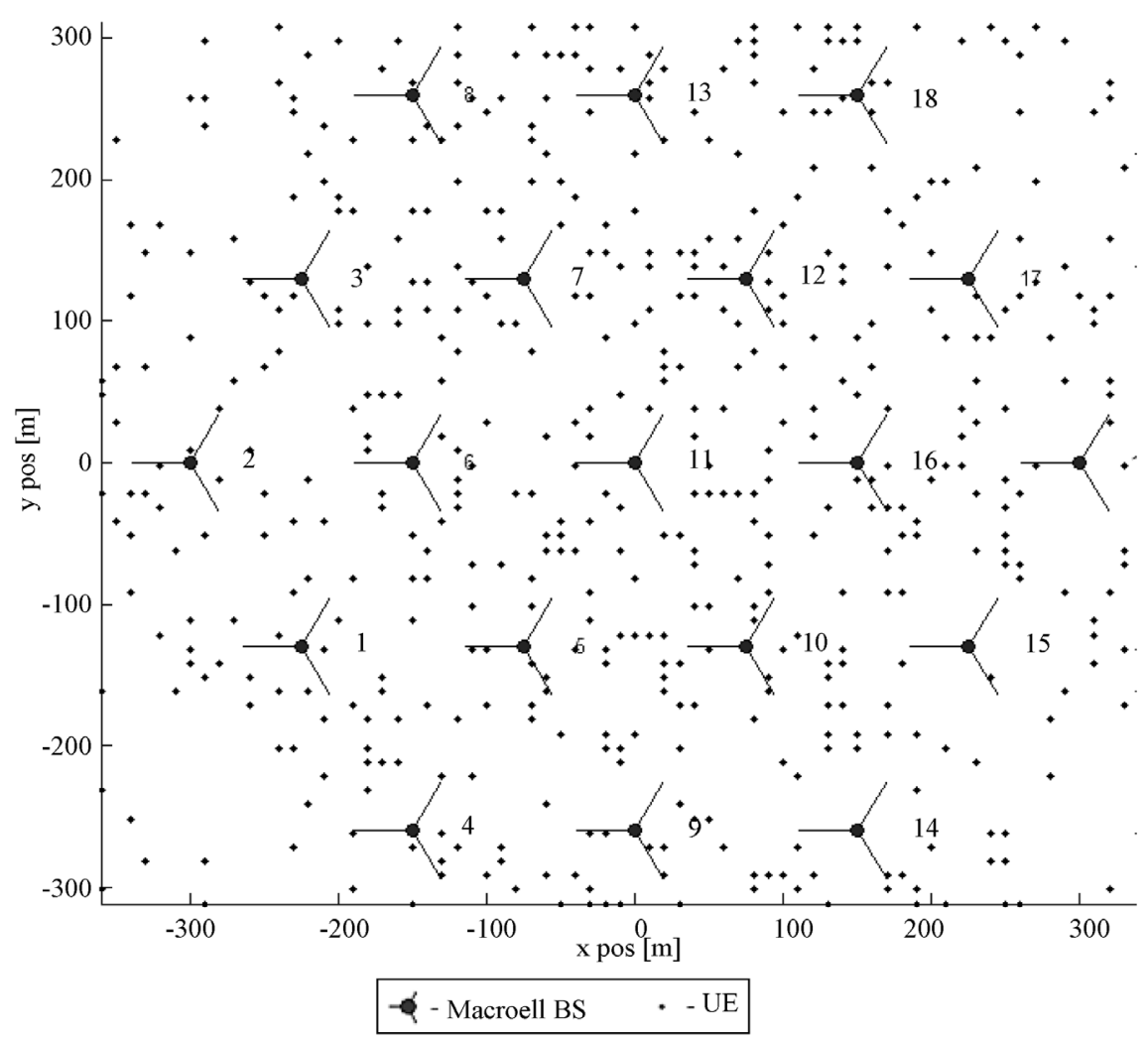

Figure 1. Small cell network deployment. 


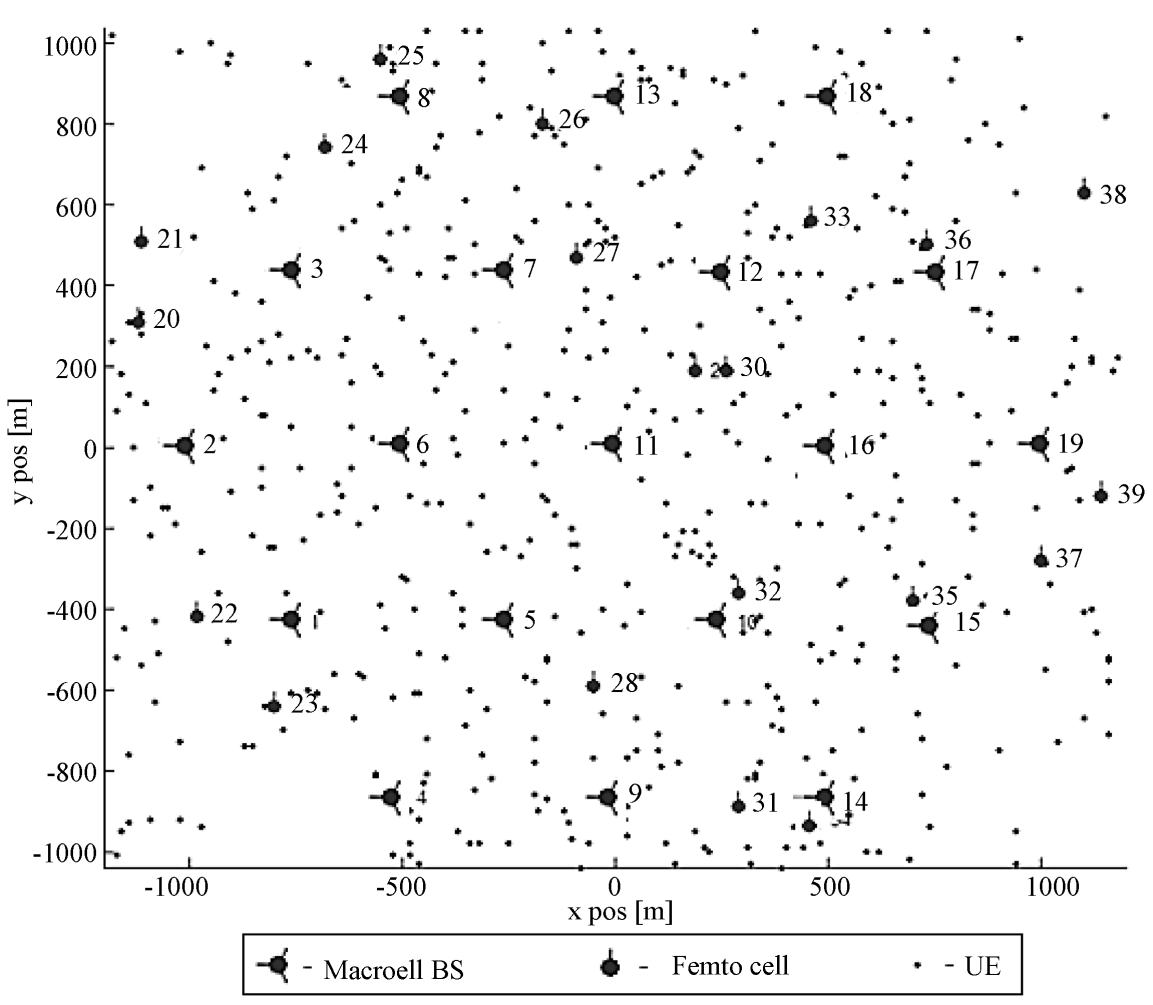

Figure 2. Heterogeneous network deployment.

domly placed and denoted as red dot in the figures. Thus, comprising with macro and femto a ubiquitous heterogeneous network (Figure 2) is formed. Proportional fair $(\mathrm{PF})$ resource scheduling algorithm is used for our simulation purposes which gives comparatively better throughput and acceptable fairness index among the UEs.

\section{Simulation}

To simulate small cell and heterogeneous network, LTE system level simulator [13] was used for $2 \times 2$ MIMO systems and zero fading channels, with a total number of 570 stationary UEs which are randomly placed within the simulation region.

Several transmission modes are available e.g. transmit diversity $(T \times D)$, closed loop spatial multiplexing (CSLM) and open loop spatial multiplexing mode (OLSM) to improve the overall data coverage and throughput.

In the simulation, CLSM mode is considered to compare the various performance parameters between small cell and heterogeneous network. CLSM mode is selected as it provides information back to the BSs e.g. rank indicator, CQI and uses pre-coding matrix indicator (PMI) which helps to adjust with the channel condition. Mutual information based effective SINR mapping (MIESM) is used to execute Link quality prediction in response to UEs SINR because of its accuracy than some other well known methods such as exponential effective SINR mapping (EESM) [14] [15]. Several Resource scheduling algorithms are available e.g. proportional fair, best CQI, Round Robin. Among them propor- 
tional fair provides better throughput for the UEs but prioritize among them. In contrast Round Robin provides best fairness and does not prioritize among the UEs but providing comparatively lower throughput. For still cases, Proportional Fair (PF) provides a higher throughput and if the users are on mobile cases Round Robin (RR) algorithm will outperform proportional fair (PF) [10]. Thus, for the simulation purposes as the UEs are in still condition proportional fair is taken as a better choice [16] [17]. Other parameters that are used for our simulation purposes are tabulated in Table 1.

\section{Results and Discussion}

Following the simulations from the previous section, the UE results are illustrated in Figure 3. The probability distribution function (PDF) of the UEs SINR in small cell and Heterogeneous network are depicted in Figure 4 and Figure 5

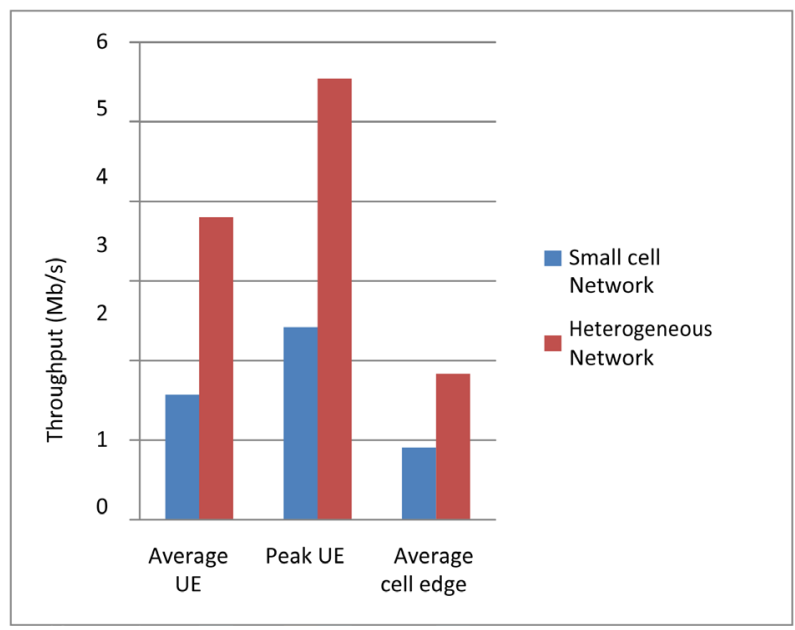

Figure 3. UE and cell edge throughputs for small cell vs. heterogeneous network.

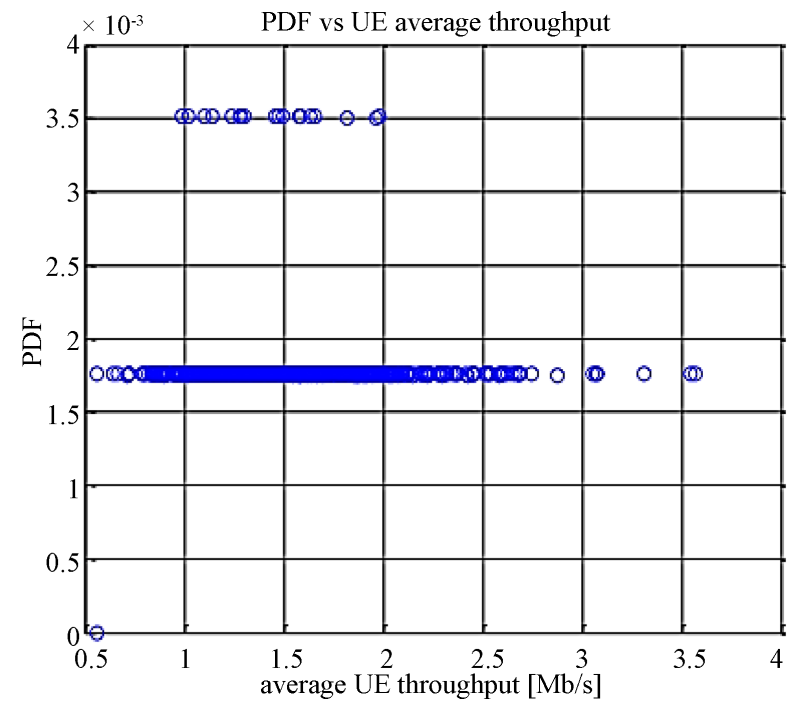

Figure 4. PDF vs. average UE throughput for small cell network. 


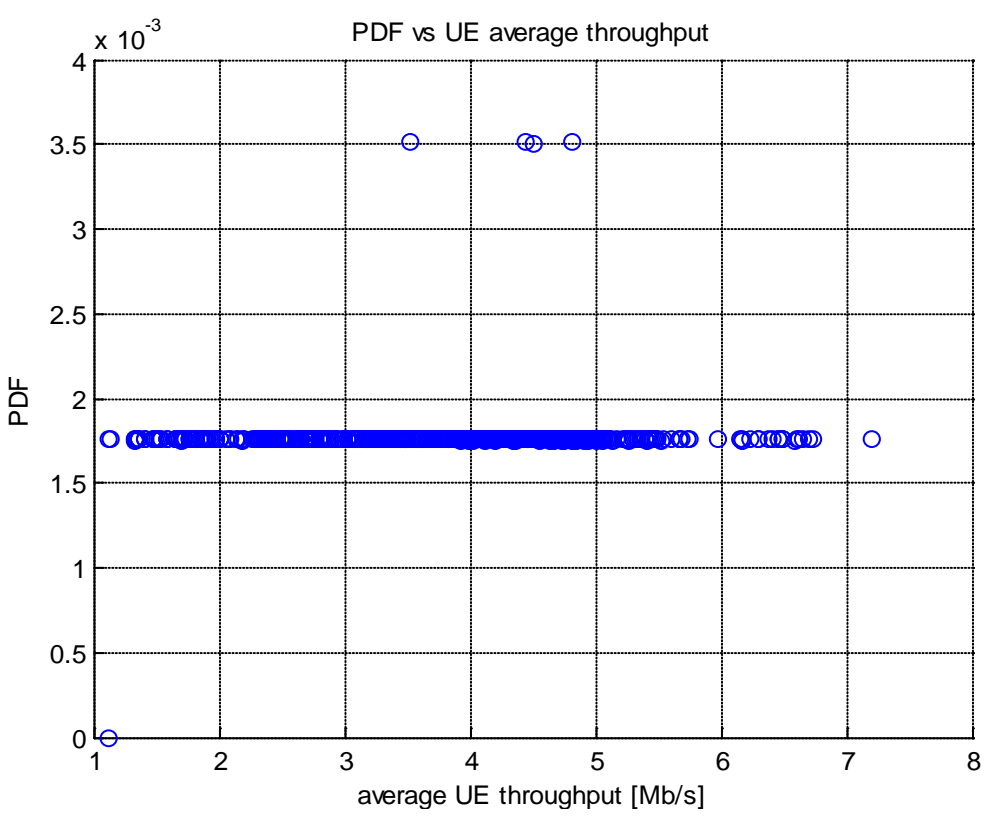

Figure 5. PDF vs. average UE throughput for Heterogeneous network.

Table 1. Simulation parameters for small cell network and heterogeneous network.

\begin{tabular}{cc}
\hline \multicolumn{2}{c}{ Simulation parameters } \\
Channel model & WINNER+ \\
Frequency & $900 \mathrm{MHz}$ \\
Bandwidth & $10 \mathrm{MHz}$ \\
No. of transmitter & 2 \\
No. of receiver & 2 \\
Transmission mode & Close Loop Spatial Multiplexing (CLSM) \\
BS height & $20 \mathrm{~m}$ \\
BS power & $45 \mathrm{~dB}$ \\
Receiver height & $1.5 \mathrm{~m}$ \\
Adaptive RI & 2 \\
Antenna azimuth offset & $30^{\circ}$ \\
Antenna gain & $15 \mathrm{dBi}$ \\
BS transmitter power & $45 \mathrm{dBm}$ \\
Femto cell transmission power & $10(\mathrm{Watts})$ \\
Simulation time & $50 \mathrm{TTI}$ \\
\hline
\end{tabular}

respectively. From the figures we can observe that UEs under Heterogeneous network experiences better SINR therefore achieving a higher channel quality.

From the throughput-SINR relations for small cell and heterogeneous network respectively shown in Figure 6 and Figure 7, it is clear that a comparatively higher throughput can be achieved using Heterogeneous network.

As the femto cells position in heterogeneous network are random and located 


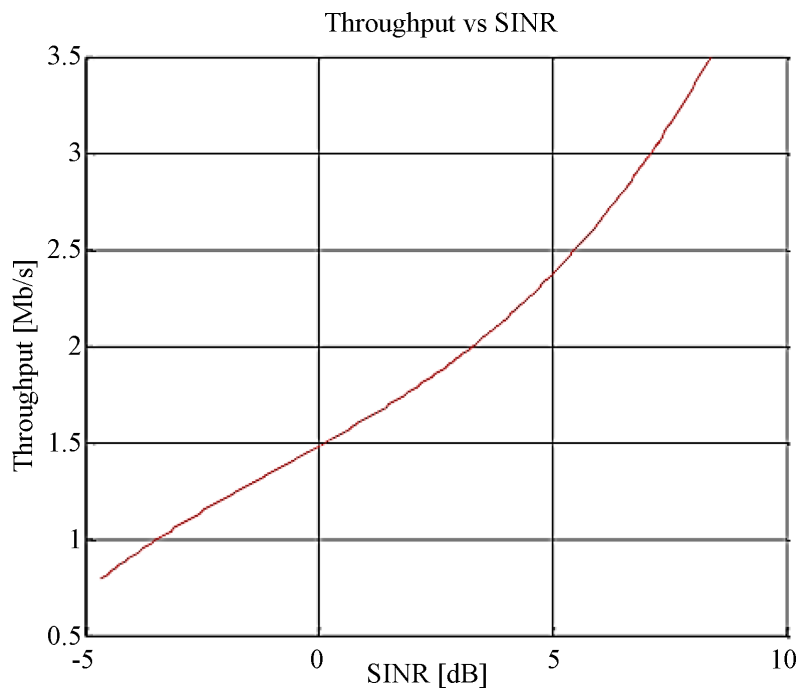

Figure 6. Average UE throughput vs. SINR for small cell network.

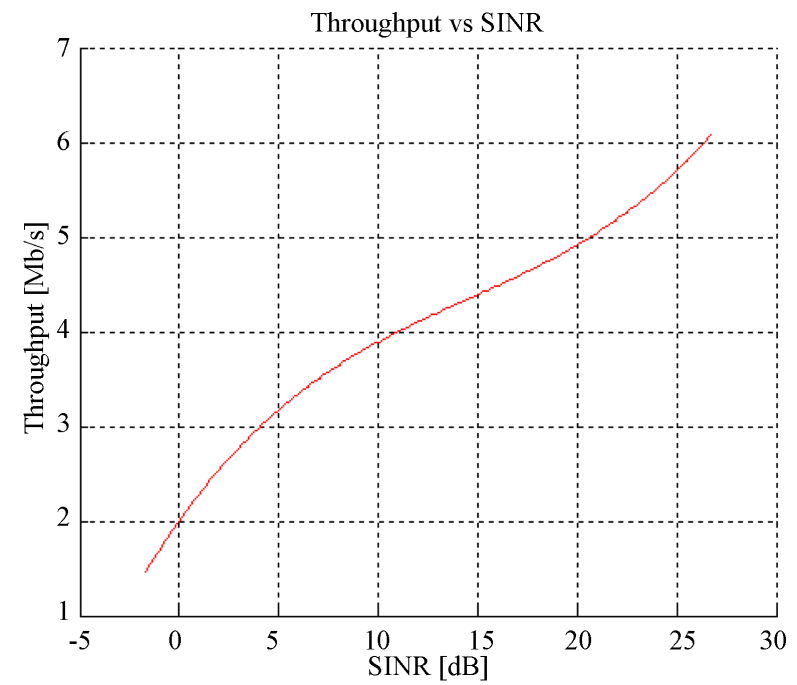

Figure 7. Average UE throughput vs. SINR for Heterogeneous network.

closer to the UEs and a better channel quality with more Cells results in a higher average UE, average cell and peak UE throughputs. Peak UE throughput is obtained with $95 \%$ of throughput ECDF and cell edge throughput with 5\% throughput ECDF. A higher average UE throughput for a given bandwidth leads to a greater average spectral efficiency for heterogeneous network UEs comparatively than small cell network UEs.

The resulting average UE spectral efficiencies for small and Heterogeneous network are shown in Table 2 and Spectral efficiency relations with SINR are depicted in Figure 8 for small cell and for Heterogeneous network in Figure 9.

So far we have discussed the impact of network type from the UE perspective. But to draw a conclusion on which type of network is most suitable in densely populated urban area requires further insight. For this purpose we will analyze 


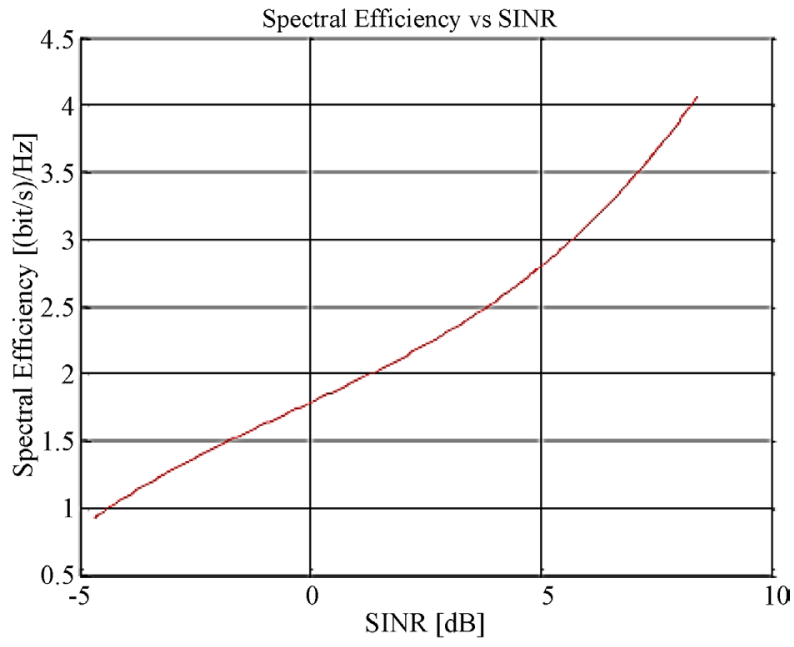

Figure 8. Spectral efficiency vs. SINR for small cell network.

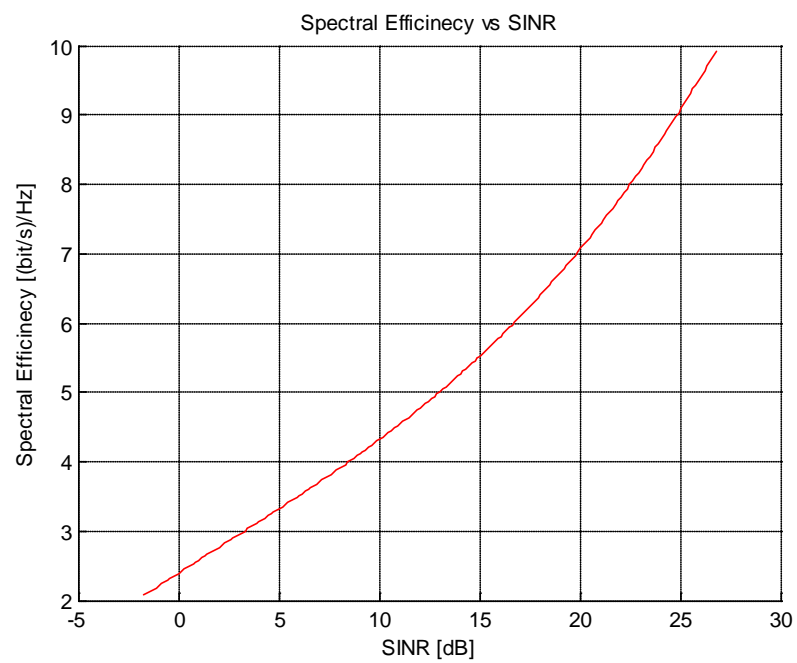

Figure 9. Spectral efficiency vs. SINR for heterogeneous network.

Table 2. Performance parameter comparison between small and heterogeneous network.

\begin{tabular}{ccc}
\hline Parameters & Small cell network & Heterogeneous network \\
\hline Fairness index & 0.92 & 0.90 \\
Average UE spectral efficiency $(\mathrm{bit} / \mathrm{cu})$ & 1.87 & 4.77 \\
Average cell throughput $(\mathrm{Mb} / \mathrm{s})$ & 15.65 & 28.13 \\
Area throughput $\left(\mathrm{Mb} / \mathrm{s} / \mathrm{km}^{2}\right)$ & 2485.8 & 541.5 \\
\hline
\end{tabular}

some additional parameters: Cell throughput and area throughput. Here $A_{t h}, N_{U E}$ and $N_{\text {Cell }}$ represents average UE throughput, total number of user equipments and total number of Cells respectively.

Throughput per cell $\left(\right.$ Cell $\left._{t h}\right)$ was calculated using the following equation:

$$
\text { Cell }_{\text {th }}=\frac{N_{U E} A_{t h}}{N_{\text {cell }}}
$$


To address the issue with high user density we have calculated throughput per unit area $\left(T h_{\text {area }}\right)$ from the equation below:

$$
T h_{\text {area }}=\frac{N_{U E} A_{t h}}{\text { Geometrical Area }}
$$

where the geometrical area, depending on BSs distribution, was obtained from the simulation. The results of both of these parameters for small and Heterogeneous network are depicted in Table 2. Since average UE throughput under Heterogeneous network is higher, as explained above, therefore a higher cell throughput is justified. But area throughput for small cell is far well better than heterogeneous network and this may be relevant due to geometrical nature of the small cell. Moreover, for both small cell network and heterogeneous network, we are having similar fairness index as proportional fair scheduler used for both the cases.

Figure 10 illustrates that, average UE throughput is decreasing with the increase of number of user for both small cell and heterogeneous network. As the resource blocks are limited by available fixed bandwidth and having a high user density, reducing the maximum achievable single UE throughput. From the figure, it can be easily seen that heterogeneous network outperforms small cell network in close loop spatial multiplexing mode (CLSM) under still cases.

Figure 11 denotes a clear understanding of the system bandwidth $(1.4 \mathrm{MHz}, 3$ $\mathrm{MHz}, 5 \mathrm{MHz}, 10 \mathrm{MHz}, 15 \mathrm{MHz}$ and $20 \mathrm{MHz}$ ) supported by the LTE where average UE throughput is measured under proportional fair (PF) scheduler algorithm for still cases. From the figure, it can be observed that for all the LTE supported system bandwidth average UE throughput is higher for heterogeneous network than small cell network under PF scheduler algorithm and as the system bandwidth increases the difference of average UE throughput between heterogeneous network and small cell network is also increased. It gives a clear idea that for all available spectrums, UEs efficiently use the system bandwidth to

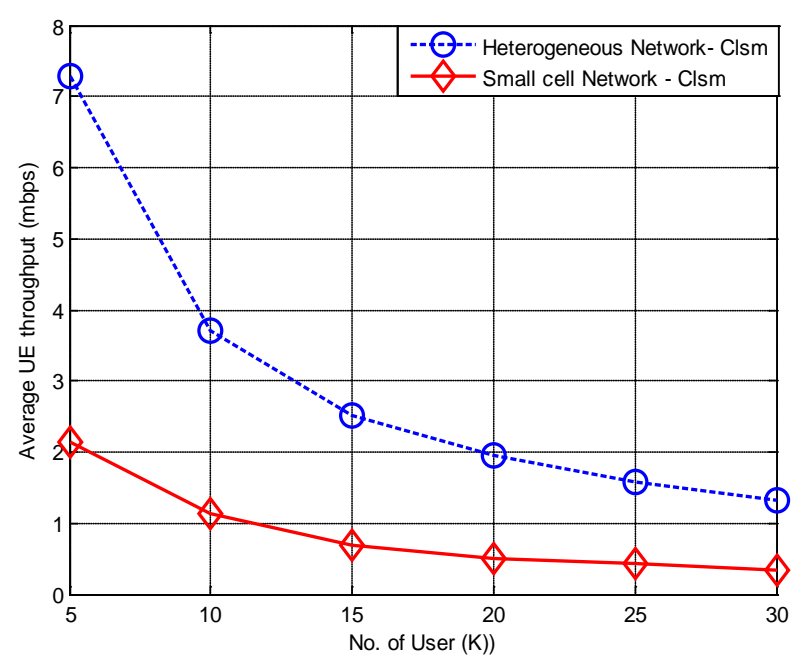

Figure 10. Average UE throughput vs. UE density for small cell and heterogeneous network under proportional fair scheduling algorithm in CLSM mode. 
transfer data and heterogeneous network will be preferable over small cell network for getting higher data rate and providing better user experience.

As the geometrical area depends upon BSs distribution and from the simulation result depicted in Figure 12 it is observed that, for all LTE supported bandwidth average area throughput (mbps) $/ \mathrm{km}^{2}$ is much higher for small cell network than heterogeneous network.

It is because due to the cell deployment and network architecture which actually means a fixed hexagonal geometry. To provide a ubiquitous coverage and higher area throughput small cell is the preferable network which will be deployed for providing better service to all the users.

\section{Conclusion}

These results highlight the fact that for better user experience heterogeneous

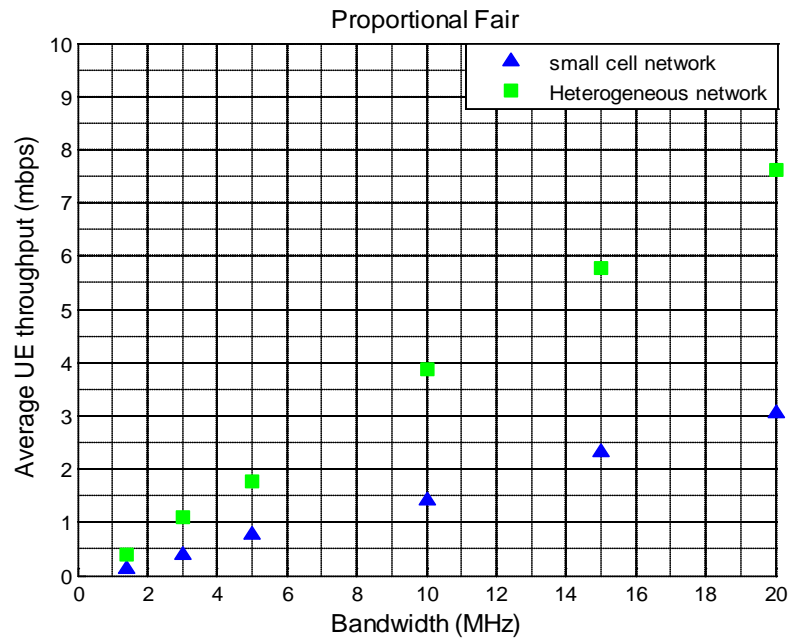

Figure 11. Avg. UE throughput vs. system bandwidth under PF scheduler for still cases.

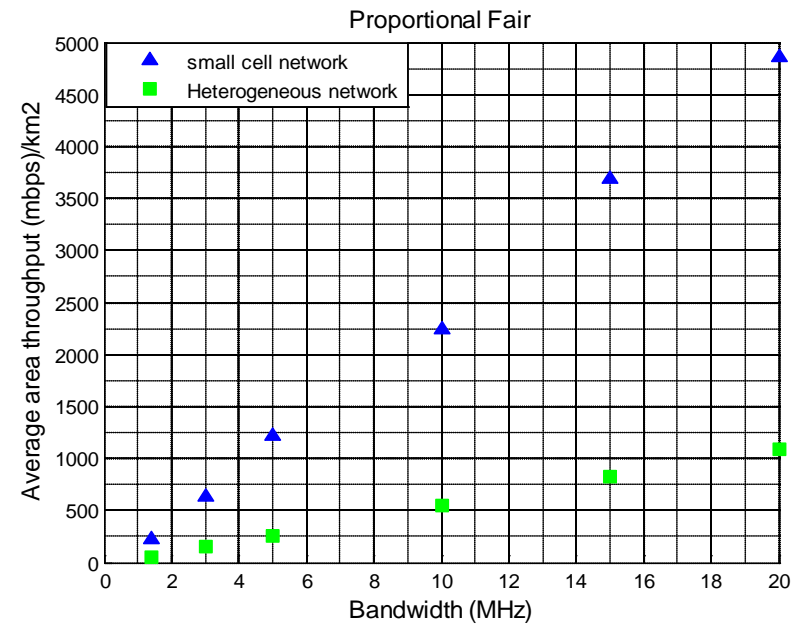

Figure 12. Average area throughput vs. system bandwidth under proportional fair (PF) scheduler algorithm for still cases. 
network is preferable but in densely populated regions to provide better service to all the users small cell is the logical network type to be used due to its higher area throughput, approximately four and half times higher than heterogeneous network according to our simulation results. Moreover for a given coverage area, small cell network requires a higher number of BSs, since it has a fixed hexagonal geometry, therefore capital expenditure (CAPEX) requirement is also higher. Femto cells used in heterogeneous network in contrast have a random distribution therefore it can be placed only at strategic points in highly populated areas, minimizing the BSs requirement for optimum coverage, thereby reducing the overall CAPEX. In future, our work will be carried out for various transmission modes and will also try to find out the effect of mobility on different MIMO modes and scheduler schemes under different network architecture.

\section{Acknowledgements}

This work is carried out with the help of LTE System Level Simulator v1.6r885 by Institute of Communication and Radio Frequency Engineering, Vienna University of Technology, Vienna.

\section{References}

[1] Ali-Yahiya, T. (2011) Understanding LTE and Its Performance. Springer, New York. https://doi.org/10.1007/978-1-4419-6457-1

[2] Tolstrup, M. (2015) Indoor Radio Planning: A Practical Guide for 2G, 3G and 4G. 3rd Edition, Wiley, Hoboken.

[3] 4G Americas (2015) Mobile Broadband Evolution towards 5G: Rel-12 \& Rel-13 and Beyond.

[4] Andrews, J. (2013) Seven Ways that HetNets Are a Cellular Paradigm Shift. IEEE Communications Magazine, 51, 136-144. https://doi.org/10.1109/MCOM.2013.6476878

[5] Andrews, J.G., Claussen, H., Dohler, M., Rangan, S. and Reed, M. (2012) Femtocells: Past, Present, and Future. IEEE Journal on Selected Areas in Communication, 30, 497-508. https://doi.org/10.1109/JSAC.2012.120401 http://www.academia.edu/2837483/Femtocells_Past_present_and_future

[6] Barayan, Y. and Kostanic, I. (2013) Performance Evaluation of Proportional Fairness Scheduling in LTE. Proceedings of the World Congress on Engineering and Computer Science (WCECS), 2, 712-717.

[7] Jahid, A., Shams, A.B. and Hossain, M.F. (2016) Energy Cooperation among BS with Hybrid Power Supply for DPS CoMP Based Cellular Networks. IEEE Conference on Electrical, Computer and Telecommunication Engineering (ICECTE), Rajshahi, Bangladesh, 8-10 December 2016, 1-4. https://doi.org/10.1109/icecte.2016.7879627

[8] Shams, A.B., Jahid, A. and Hossain, M.F. (2017) A CoMP Based LTE-A Simulator for Green Communications. International Conference on Wireless Communications, Signal Processing and Networking (WiSPNET), Chennai, India, 22-24 March 2017.

[9] Jahid, A., Shams, A.B. and Hossain, M.F. (2016) PV Powered CoMP Based Green Cellular Networks with Standby Grid Supply. International Journal of Photoenergy, 2016. 
[10] Shams, A.B., Abied, S.R. and Hoque, M.A. (2016) Impact of User Mobility on the Performance of Downlink Resource Scheduling in Heterogeneous LTE Cellular Networks. $3^{\text {rd }}$ International Conference on Electrical Engineering and Information \& Communication Technology (iCEEiCT), Dhaka, 22-24 September 2016. https://doi.org/10.1109/ceeict.2016.7873091

[11] Habaebi, M.H., Chebil, J., Al-Sakkaf, A.G. and Dahawi, T.H. (2013) Comparison between Scheduling Techniques in Long Term Evolution. IIUM Engineering Journal, 14, 66-75.

http://journals.iium.edu.my/ejournal/index.php/iiumej/article/view/354

[12] Shams, A.B., Abied, S.R., Asaduzzaman, Md. and Hossain, M.F. (2017) Mobility Effect on the Downlink Performance of Spatial Multiplexing Techniques under Different Scheduling Algorithms in Heterogeneous Network. International Conference on Electrical, Computer and Communication Engineering 2017 (ECCE 2017), Cox's Bazar, Bangladesh, 16-18 February 2017.

[13] LTE System Level Simulator v1.6r885 by Institute of Communication and Radio Frequency Engineering. Vienna University of Technology, Vienna.

[14] Olmos, J., Ruiz, S., García-Lozano, M. and Martín-Sacristán, D. (2010) Link Abstraction Models Based on Mutual Information for LTE Downlink. COST 2100 TD(10)11052 Report.

[15] Wan, L., Tsai, S. and Almgren, M. (2006) A Fading-Insensitive Performance Metric for a United Link Quality Model. Proceedings of WCNC 2006, Las Vegas, 3-6 April 2006, 2110-2114.

[16] Sesia, S., Toufik, I. and Baker, M. (2009) LTE-The UMTS Long Term Evolution-From Theory to Practice. Wiley, Hoboken.

http://www.cs.odu.edu/ rnagella/LTE-simulation/Wiley.LTE.The.UMTS.Long.Ter m.Evolution.From.Theory.to.Practice.2nd.Edition.0470660252.pdf

[17] Kawser, M.T., Farid, H.M.A.B., Hasin, A.R., Sadik, A.M.J. and Razu, I.K. (2012) Performance Comparison between Round Robin and Proportional Fair Scheduling Methods for lte. International Journal of Information and Electronics Engineering, 2, 678-681.

Submit or recommend next manuscript to SCIRP and we will provide best service for you:

Accepting pre-submission inquiries through Email, Facebook, LinkedIn, Twitter, etc. A wide selection of journals (inclusive of 9 subjects, more than 200 journals)

Providing 24-hour high-quality service

User-friendly online submission system

Fair and swift peer-review system

Efficient typesetting and proofreading procedure

Display of the result of downloads and visits, as well as the number of cited articles

Maximum dissemination of your research work

Submit your manuscript at: http://papersubmission.scirp.org/

Or contact jcc@scirp.org 